\title{
The impact of linguistic proximity and diglossia on brand name and slogan extension tendencies in the Turkish, Russian and Arabic contexts
}

\author{
Djavlonbek Kadirov ${ }^{1}$ (D) Ahmet Bardakcı $^{2} \cdot$ Murat Kantar $^{3}$
}

Published online: 21 August 2017

(C) Macmillan Publishers Ltd 2017

\begin{abstract}
The impact of linguistic proximity and diglossia on multinational corporations' visual identity extension strategies in multiple sociolinguistically different markets is investigated. Specifically, this study focuses on a sample of Fortune Global 500 corporations and explores their brand name/slogan extension practices in three distinct linguistic contexts: Turkish, Russian and Arabic. The study reveals that the different levels of linguistic proximity systematically influence brand name adaptation including brand name transliteration, as well as slogan translation and new slogan creation in English. The study also finds that these tendencies non-systematically but significantly vary across the levels of diglossia. Conversely, diglossia systematically influences slogan standardization and new slogan creation in a local language, while the effect of linguistic proximity on these practices is non-systematic.
\end{abstract}

Keywords Brand · Slogan · Linguistic proximity · Meta-semantics $\cdot$ Diglossia

Djavlonbek Kadirov

djavlonbek.kadirov@vuw.ac.nz

Ahmet Bardakc1

abardakci@pau.edu.tr

Murat Kantar

mkantar@pau.edu.tr

1 Victoria Business School, Victoria University of Wellington, Rutherford House, 1109, 23 Lambton Quay, Pipitea Campus, Wellington 6140, New Zealand

2 Pamukkale Üniversitesi İktisadi ve İdari Bilimler Fakültesi, İşletme (İngilizce) Bölümü, Kınıklı Yerleşkesi, 20070 Denizli, Turkey

3 Pamukkale Üniversitesi İktisadi ve İdari Bilimler Fakültesi, Uluslararası Ticaret ve Finansman Bölümü, Kınıklı Yerleşkesi, 20070 Denizli, Turkey

\section{Introduction}

One of the pivotal topics in research on global marketing is corporate visual identity extension decisions (Schmid and Kotulla 2011; Walters 1986; Jain 1989; Boddewyn and Grosse 1995; Terpstra and Sarathy 2000; Hollensen 2004; Fastoso and Whitelock 2007). The most visible elements of corporate identity from the perspective of consumers are brand name and slogan (Jun and Lee 2007; Erdogmus et al. 2010). These elements are seen as the building blocks of business communication (Quelch 1999; Alashban et al. 2002). The American Marketing Association defines brand name as "the part of a brand that can be spoken which includes letters, numbers, or words" (the AMA 2017). This part of a brand is predominantly represented in writing (Zhang and Schmitt 2001). Slogan, which is also referred to as a tagline, represents "the verbal or written portion of an advertising message [or a brand] that summarizes the main idea in a few memorable words" (the AMA 2017). This study explores the effect on brand/slogan extension of linguistic phenomena such as linguistic proximity and diglossia. Linguistic proximity refers to the extent to which the phonetic features of a local language in a country under focus is close to those of the base linguistic system, which is English in this study. Diglossia refers to the practices of using two different languages in the same country or community (Ferguson 1959; Hudson 2002), while perceptually treating one of the languages as more prestigious than the other.

Brand name serves as a robust signal of quality across different cultures, much more so than other product elements such as price or other physical attributes (Dawar and Parker 1994). Successful brand names build strong brand equity through enhancing memorability, favorability and preference for products (Aaker 1996). Selecting a proper 
brand name when entering foreign markets is a critical marketing decision (Zhang and Schmitt 2001). In fact, research shows that getting brand name/slogan right may account for more than $40 \%$ of the product's likelihood of success in global markets (Alashban et al. 2002; Zaltman and Wallendorf 1979). As MNCs expand into sociolinguistically different markets, their brand name/slogan extension decisions become increasingly complex (Schuiling and Kapferer 2004). The existing research has examined such decisions in either of the linguistically similar contexts, for example, branding decisions within the European continent (Chan and Huang 1997) or radically distinct linguistic contexts such as the USA versus China (Francis et al. 2002; Zhang and Schmitt 2001). Yet, no research has so far investigated the extent to which less extreme, but significant differences in linguistic systems such as their phonetic and meta-semantic features impact brand name and slogan extension decisions. For instance, the phonographic system comprises a large number of different linguistic variants that differ in script, phoneme recording styles, orthography and syllabic features. In addition, a linguistic variant is defined by its predominant meta-semantic structure, i.e., the cultural meaning of language use as it relates to both the local and foreign registers. To the best of our knowledge, there is no research in the field that considers how aforementioned variations in different linguistic contexts influence brand/slogan extension decisions. To address this gap, the current study investigates how a sample of Fortune 500 Global corporations extends their brands and brand-associated slogans into three distinct linguistic contexts: Turkish, Russian and Arabic.

It is critical for businesses (re)assessing their brand/ slogan extension strategies in emerging markets to understand the impact of linguistic similarities and language use symbolism, as language is the key medium through which brand meanings are communicated (Francis et al. 2002; Lowrey and Shrum 2007). The complexity of such assessment is exacerbated by the fact that different cultures may feature different levels of proximity and diglossia, which may in turn differentially impact on how markets enable or hinder integration of visual identity elements. For example, in the Middle East Toyota recently adopted a unique hybrid strategy whereby the tagline featured the word "Akeed" written in Arabic letters while the brand name retained its standardized global form. This approach contrasts the customary practice of adapting brand names through transliteration while keeping taglines unchanged. Hence, in light of the symbolism of language use and its various phonetic features, it is very important to develop systematic assessment of the viability of such hybrid, nonintegrated extension strategies. In brief, the current study reveals that linguistic proximity is negatively associated with brand name adaptation and brand name transliteration, as well as the creation of new slogans in English, while being positively associated with the translation of slogans into a host language in a systematic fashion (i.e., the highmedium-low levels of proximity lead to the corresponding high-medium-low levels of brand identity extension modes). At the same time, proximity significantly influences slogan adaptation and the creation of new slogans in a host language in a non-systematic way (high-mediumlow proximity might, for example, lead to the mediumhigh-low slogan creation levels). In contrast, the extent to which diglossia is prevalent on a national level has a negative systematic effect on slogan adaptation and new slogan creation in a local language, whereas featuring a non-systematic positive effect on brand name adaptation, brand name transliteration and slogan creation in English.

The contributions of this study are manifold. First, this study shows that brand name localization is prevalent not only when there is a radical inter-linguistic systems shift (e.g., from phonographic to logographic) (Francis et al. 2002; Zhang and Schmitt 2001), but also when linguistic and meta-semantic features gradually change within the same linguistic system, specifically within the phonographic family of languages. Second, by analyzing the localization patterns of both brands and slogans, the study finds a complex set of systematic and non-systematic effects that are not fully explored in the extant literature. Finally, the study conceptualizes and examines the differential effects of two specific factors, linguistic proximity and diglossia, which are understudied in the previous research.

\section{Theoretical background}

\section{The typology of brand/slogan extension practices}

Since brand names and slogans are complex combinations of pictographs, alphabetic elements, signs and iconic content, they are usually extended to other sociocultural contexts along the phonetic and semantic dimensions which together make up the textual identity of the brand (Usunier and Shaner 2002). The phonetic dimension refers to sounds associated with linguistic cues (i.e., pictographs, letters, signs), whereas the semantic dimension refers to meanings evoked by people when they see or hear the brand. A brand/slogan and its adapted extension can be: (a) phonetically and semantically similar; (b) phonetically similar but semantically different; (c) semantically similar but phonetically different; or d) both phonetically and semantically different. Based on these combinations, four extension strategies can be identified. These strategies are given in Table 1. 
Table 1 Brand/slogan extension strategies

\begin{tabular}{ll}
\hline Meaning (semantic) & \\
\hline Similar & Different \\
\hline Sound (phonetic) & \\
Similar & \\
Transliteration/translation (Francis et al. 2002) & Transliteration (Francis et al. 2002; Fan 2002) \\
Dual adaptation (Fetscherin et al. 2012) & Sound adaptation (Fetscherin et al. 2012) \\
Dual extension (Alon et al. 2009) & Brand feeling extension (Alon et al. 2009) \\
Literal and phonetic translation (Bruneel 2013) & Literal translation (Bruneel 2013) \\
Mixed translation (Fan 2002) & \\
Different & Creation (Francis et al. 2002) \\
Translation (Francis et al. 2002) & No dual adaptation (Fetscherin et al. 2012) \\
Meaning adaptation (Fetscherin et al. 2012) & Full (dual) adaptation (Alon et al. 2009) \\
Brand meaning extension (Alon et al. 2009) & \\
Phonetic translation (Bruneel 2013) & \\
Free translation (Fan 2002) & \\
Standardization & \\
\hline
\end{tabular}

The most complex brand extension practice is dual adaptation that refers to the practice of extending an original brand to a new sociocultural context where its localized version becomes both phonetically and semantically identical (Fetscherin et al. 2012). The strategy is also called phono-semantic translation (Zhang and Schmitt 2001). Buick, Chrysler, Martell, Adidas, KFC, McDonald's and Walmart implemented this strategy to varying degrees in China (Alon et al. 2009). For these companies, the task has been simplified by the fact that, in Mandarin, various combinations of ideograms can be used to imitate similar sounds as well as meanings (Alon et al. 2009; Fetscherin et al. 2012; Francis et al. 2002).

The meaning adaptation (i.e., translation) strategy is based on retaining the meaning of the brand, while its phonetic component is allowed to differ. This strategy appears to be common for multinationals operating in China (Alon et al. 2009; Bruneel 2013; Fan 2002; Fetscherin et al. 2012; Francis et al. 2002). The strategy is based on the suggestiveness principle according to which the brand name should convey attribute or benefit information (Keller 1993; Keller et al. 1998). Alon et al. (2009) report that GM, Mustang, Triumph, GE, Holiday Inn and 7-Up use meaning adaptation in China. In contrast, sound adaptation (i.e., transliteration) occurs when the sounds associated with the brand remain unchanged. Transliteration can be difficult as well, since it is not easy to attain harmony in pronunciation (Alon et al. 2009). Some research reveals that meaningless names, albeit phonetically standardized, face difficulties in foreign markets (Fetscherin et al. 2012; Francis et al. 2002). The creation strategy is based on building a new brand name that has no phonetic or semantic relationship with the original. This strategy means complete (full) localization. Sheraton, Pizza
Hut, Marlboro and Duracell are examples of brands that utilize this strategy in China (Alon et al. 2009). A new brand would enable the firm to adopt a new identity and avoid problems that are normally linked to linguistics differences (Francis et al. 2002). This strategy can also help avoid possible negative connotations that might arise due to the use of a standard version ( $\mathrm{Li}$ and Shooshtari 2003).

\section{Linguistic variation and brand/slogan extension}

The linguistic content of brand names/slogans influences how consumers interpret and understand these symbols (Usunier and Shaner 2002). Researchers advise that brand identity extension studies should go beyond studying brands in similar linguistic contexts (Onkvisit and Shaw 1999), as findings based on comparisons in the context of very similar languages may not be generalizable into contexts where significant localization must be accomplished (Chan and Huang 1997; Francis et al. 2002). This line of argument has been advanced by a number of researchers who focused on major differences between the phonographic (Western) and logographic (Far East) systems (Zhang and Schmitt 2001). However, there are less contrasting differences in alphabetic writing and phonosemantic dynamics within each group of linguistic systems. For example, the phonographic writing system includes Roman, Cyrillic and Arabic alphabets. Although the commonly accepted standard for writing brand names is the Latin alphabet (Usunier and Shaner 2002), the importance of the Cyrillic and Arabic alphabets must not be underestimated as these writing systems are employed by a significant proportion of the world population. Moreover, within each of these groups, there are many variations. For example, the Turkish or Baltic adaptation of the Latin 
writing system can be compared to the Eastern European, Caucasian and Central Asian adaptations of Cyrillic, and also to the Persian, Urdu and North African adaptations of Arabic.

Assuming that the base language for multinational firms is English, the task of extension will depend on the extent to which the writing system in a host country differs from the English version of the Latin writing system. In general, the other adaptations of Latin are very close to English, while phonetic differences become increasingly discernible as the context shifts to the variants of Cyrillic and then toward those of Arabic. Differences between the writing systems also influence phonetic capacity, that is, pronunciation. The difficulty of pronunciation greatly influences consumer awareness, recall, brand-related consumer interactions and purchase likelihood (Alashban et al. 2002). Moreover, pronouncing foreign words written in a distinct script may not only be difficult, but also humiliating (Usunier and Shaner 2002). As a result, markets create pressure to implement adaptive extensions of brand/slogans in countries with less phonetic proximity. Considering all these factors, it is expected that brand extension decisions will depend on the extent to which the local variant of the writing system is different from the base variant. In other words, the likelihood of adaptation will progressively increase as firms switch from similar alphabetic writing systems to increasingly distinct ones.

Hypothesis 1a: The less the proximity between the phonetic features of alphabetic writing variants, the greater the likelihood of brand adaptation.

In contrast, slogan extension decisions represent a qualitatively different context. Research shows that branding and advertising adaptation decisions are independent (Sandler and Shani 1992). Specifically, adapting ads is considered to be more difficult than adapting brand names (Fatt 1967; Sandler and Shani 1992; Usunier and Shaner 2002). Even though slogans are not the same as advertising, they constitute the key content of most advertising. Since slogans are idiomatic expressions, the lack of adaptation would hinder a clear transfer of subtle meanings imbued in such idioms (Fatt 1967). Moreover, the suggestiveness principle (Keller et al. 1998) extended to the slogans context motivates a prediction that full adaptation will be more preferred because connotative meanings expressed in one language become incomprehensible in a different linguistic context (Usunier and Shaner 2002). Because slogans represent a complex combination of words that express unique cultural meanings, a typical expectation would be that, ceteris paribus, firms would be inclined toward adaptation. However, in reality slogan-related decisions are not as straightforward as assumed. Phonetic differences may turn out to be prohibitive to the extent that slogan adaptation radically decreases. This view hinges on the equivalence principle of translation which posits that slogan translation is easier when the languages are more or less equivalent in terms of functional, stylistic and semantic features (Nord 1994).

Hypothesis 1b: The greater the proximity between the phonetic features of alphabetic writing variants, the greater the likelihood of slogan adaptation.

Conceptually, the social use of languages and their perceived status vis-à-vis each other is important (Ferguson 1959). This study borrows several key concepts from sociolinguistics to explain brand/slogan extension dynamics. Meta-semantics refers to the meaning of language use, as opposed to semantics, which refers to the meanings of words and phrases. The examination of meta-semantics is desirable in situations when foreign words are inserted into daily conversations, specifically market communication. One such meta-semantic concept is diglossia which refers to the practice of using two different languages in the same country or community (Ferguson 1959; Hudson 2002). Diglossia occurs when one of the languages is seen as more prestigious. Most often, due to long-term historical dynamics in developing countries a Western language may become considered more prestigious than the local register. In such instances, the foreign language is seen a symbol of modernity (Hornikx et al. 2010) and social status (Hudson 2002). For instance, in bilingual cultures (e.g., India, Japan, Korea) people use English as the second language, where it represents modernity, progress, sophistication and a cosmopolitan lifestyle (Bhatia 2000; Krishna and Ahluwalia 2008; Piller 2003; Takashi 1990). In other words, these societies deem a higher extent of English diglossia as appropriate. As diglossia becomes prevalent in society, the prestigiousness effect is created through foreign/local contrasts. Therefore, companies will increasingly use brand adaptation options based on mixing foreign and local symbols. For example, in the Middle Eastern countries' corporations tend to present global brands in combination with local transliteration.

Hypothesis 2a: The greater the extent of perceived appropriateness of the base language diglossia, the greater the likelihood of brand adaptation.

However, diglossia might lead to less adaptation when it comes to slogans. Understanding the meaning of a message in a foreign language used in slogans is not a prerequisite of a diglossic effect. Research shows that people could still recognize the message as the prestigious foreign language and then activate positive stereotypes about the "advanced" culture (Hornikx et al. 2010). In developing countries, famous global brands are seen as symbols of power, wealth and luxury. A recent study finds that consumers, specifically in the Middle East, tend to not only 
envy but also crave the wealth, power and modernity of the Western world (Sobh et al. 2014). In such cases, using original or mixed language ads is found to be the best strategy (Krishna and Ahluwalia 2008). Also, some researchers refer to Ibn Khaldun's theory of sociological imitation, reflected in the expectation that weak nations imitate dominant nations, to explain a counterintuitive tendency of full slogan standardization in the Middle East (Bardakci and Akinci 2014). Hence,

Hypothesis 2b: The greater the extent of perceived appropriateness of the base language diglossia, the less the likelihood of slogan adaptation.

\section{Method}

\section{Research context}

The current study compares the brands and associated taglines (i.e., slogans) of Fortune 500 Global corporations within three different linguistic contexts: Turkish, Arabic and Russian. In this study, the key assumption is that the base linguistic context (i.e., the origin) for corporate identity extension decisions is English, although it must be recognized that these corporations are in fact based in the different parts of the globe. Although Turkish, Arabic and Russian are significantly different than English, they are still situated within the same overarching group of languages which is referred to as phonographic. This fact makes the linguistic context differences under focus less extreme as well as more nuanced when compared to those arising from a comparison of phonographic versus logographic language settings (Zhang and Schmitt 2001).

\section{Measuring proximity and diglossia levels}

To assess phonetic proximity and diglossia levels for each linguistic context, the authors conceptualized and developed a number of criteria for measurement. These criteria are given in Tables 2 and 3 for proximity and diglossia, respectively.

Notably, the phonetic systems given in Table 2 fall under the "segmental" group of scripts that is different to the pictographic, ideographic, logographic and syllabaric groups. In a segmental script, graphemes (i.e., symbols) in

Table 2 Differences between the phonetic systems of the linguistic contexts

\begin{tabular}{|c|c|c|c|}
\hline \multirow[t]{2}{*}{ Criteria } & \multicolumn{3}{|l|}{ Linguistic contexts } \\
\hline & Turkish & Russian & Arabic \\
\hline Group of script & Segmental $^{\mathrm{a}}$ & Segmental $^{\mathrm{a}}$ & Segmental $^{\mathrm{a}}$ \\
\hline Script & Latin $^{\mathrm{a}}$ & Cyrillic & Arabic \\
\hline System of recording phonemes & True $^{\mathrm{a}}$ & True $^{\mathrm{a}}$ & Abjad \\
\hline Orthography & Highly Phonemic & Morphophonemic & Consonant based \\
\hline Syllabic feature & None $^{a}$ & Partially syllabic & Syllabic \\
\hline Direction of writing & Left to right ${ }^{\mathrm{a}}$ & Left to right ${ }^{\mathrm{a}}$ & Right to left \\
\hline Predominant writing style & Print $^{\mathrm{a}}$ & Print $^{\mathrm{a}}$ & Cursive \\
\hline Upper versus lower case distinction & Yes $^{\mathrm{a}}$ & Yes $^{\mathrm{a}}$ & No \\
\hline Vowels sounds & 8 & 10 & 6 \\
\hline Proximity to the base phonetic system (i.e., English) & High & medium & Low \\
\hline
\end{tabular}

Table 3 Differences between the meta-semantics of the linguistic contexts

\begin{tabular}{llll}
\hline Criteria & Linguistic contexts & & \\
\cline { 2 - 4 } & Turkish & Russian & Arabic \\
\hline Historical contact & Short occupation by allies & Independent & British protectorates \\
Political action & Partially dependent & Independent & Highly dependent \\
Image of English & Language of distant allies & Language of rivals & Language of allies \\
Bilingual communication involving English & Sporadic & Rare & Very common \\
Craving Western lifestyle & Mixed & Weak & Strong \\
Cultural emulation & Adaptive & Highly adaptive & Strong \\
Appropriateness of English diglossia & Medium & Low & High
\end{tabular}

a Same as English 
their different combinations directly represent phonemes (i.e., the basic units of sound). The Turkish belongs to the Altaic language family and its alphabet consists of 29 letters. It includes unique consonants (ç and $\breve{g}$ ) and vowels (1, ü, ö) which are not used in English. Also, the English letters Q, W and X do not exist in the Turkish alphabet. Although its grammatical structure is significantly different than English, its phonetic and alphabetic capacity is relatively close. The main similarity is that its script is Latin. Moreover, its alphabet is considered "true," that is, that it contains separate graphemes to represent both consonants and vowels; it has no syllabic feature which means a single grapheme representing a specific combination of a consonant and a vowel; the direction of writing is left to right and the style of writing is predominantly "print" which is nonjoint and non-cursive. The main difference from English is that its orthography is highly phonemic that is that there is a high degree of one-to-one correspondence between graphemes and phonemes, while English orthography is nonphonemic. Russian has relatively moderate proximity to English (Table 2). The modern Russian alphabet consists of 33 letters with ten vowels. It has a Cyrillic script system which is similar to Latin in terms of being a segmental, true, left to right and predominantly printed writing system. However, its orthography is morphophonemic, which means that the different forms of morphemes are spelled identically in spite of prominent pronunciation differences. Also, some graphemes in the Russian alphabet are syllabic, including ë (jo), Ю (ju) and я (ja), which do not exist in either English or Turkish orthography. In contrast, Arabic has relatively low proximity to English. The Arabic writing system has 28 consonants and eight vowels/diphthongs. The number of vowel sounds in Arabic is about one-third of English. Still being a segmental script, Arabic follows an abjad system which contains graphemes for consonants only, while vowels are only rarely indicated via diacritics. Hence, its orthography is based on spelling out consonants, whereas short vowels do not appear in most texts. Its alphabet is highly syllabic. Texts are read from right to left and written in cursive script. Another difference from the other three variants is that no distinction is made between upper and lower case, and the rules of punctuation are much looser than in English.

The authors involved four experienced academics from the linguistics department of a university located in Turkey to serve as the raters of phonetic proximity. These raters in principle endorsed our conceptualization of the proximity criteria, while helping us to make slight improvements. The inter-rater agreement rate was $92.5 \%$. In addition to their assessment, the experts noted that although both Turkish and English scripts are Latin, pronunciation of phonemes is mostly different. Thus, it should be noted that Turkish people who are not familiar with English tend to pronounce English phonemes as Turkish. To sum it up, the raters assessed Turkish as a high proximity, Russian as a medium proximity and Arabic as a low proximity linguistic system.

The linguistic contexts under focus were also assessed based on the sociolinguistics of languages. Table 3 presents the criteria and assessment of meta-semantic differences between the linguistic contexts. This assessment enabled us to derive the extent to which the diglossia concerning English is appropriate within the particular linguistic milieu.

Whether English is considered a relatively more prestigious register than the local language depends on many factors. Historically, the Middle Eastern countries were subjected to the colonial influence of British Imperialism and thus remained politically dependent on Englishspeaking alliance partners. Bilingual communication involving English is very common in these countries, while cultural emulation of the West in consumption is very strong (Sobh et al. 2014). In contrast, English diglossia in Russia tends to be low. Russia as the direct successor of the Soviet Union, and before that the Russian Empire, was barely influenced by the English-based imperial rule as it always remained a strong partner or rival. Russia bears the heritage of the lengthy "cold war" between the West and the Soviet Union. It is also influenced by a newly emerging Russian nationalism, in some cases extreme chauvinism, and appears to be a politically independent player on the global scene. In consumption, the population's emulation of the West tends to be highly adaptive. Turkey is positioned at the middle of the diglossia continuum.

The authors hired four experienced academics from the political and historical studies disciplines of a university located in Turkey to serve as the raters of diglossia. These raters in general endorsed our conceptualization of the diglossia criteria. The inter-rater agreement rate was $88.8 \%$. In addition to their assessment, the experts noted that the short occupation by the allies did not create significant diglossia effects between Turkey and the occupying forces as the occupation took place only in Istanbul. Another expert noted that in the context of political action the NATO membership of Turkey warrants the assessment of "partially dependent." An experienced expert indicated that English may not be seen as the language of distant allies by ordinary people in Turkey as it is considered as a "lingua franca," while those who are familiar with the political context take English as the language of USA which is a strategic ally of Turkey. Some experts felt that the criteria of "craving Western lifestyle" and "cultural emulation" are closely related. To sum it up, the raters assessed Arabic as a high diglossia context, Turkish as medium diglossia, while Russian as low diglossia. 


\section{Data collection and coding procedure}

The study focuses on Fortune 500 Global corporations and their brands/slogans for this investigation. The authors obtained the list of global companies from www.fortune. com. Then, for each company included in this list, they examined whether these companies operate in the following countries: USA or UK (the base linguistic system), Turkey, Russia and the Middle East (e.g., Qatar, UAE or Saudi Arabia). They identified the brand names of these companies from their relevant web pages and social media (Facebook, YouTube, Twitter and LinkedIn were included). The final sample included 149 brands which were present in all markets under focus. Three bilingual raters competent in Turkish-English, Arabic-English and Russian-English were trained to classify the brands and associated slogans according to the provided schedule. The raters had access to the list of the brands and slogans in English. They initially assessed whether a brand and its associated slogan were standardized or adapted in a particular context. For the adapted brands/slogans, these raters identified the type of an adaptation strategy. Thus, the brands/slogans were classified into one of the following groups: dual adaptation, transliteration, translation or creation which represents full adaptation in either the local language or English.

\section{Findings}

Table 4 summarizes brand extension tendencies in the three linguistic contexts. The dual adaptation strategy is prominently absent in all cases. The Chi-square goodnessof-fit test statistics for these three groups are significant. Hence, the null hypothesis that the proportion of cases in each group is equal and concludes that there are statistically significant differences in the observed proportions is rejected.
Table 4 shows that the brand adaptation incidence varies in accord with the distance of the host country's alphabetic writing system from English. Evidently, 5.4\% of the brands are adapted in Turkey (high proximity), whereas it is $14.8 \%$ in Russia (medium proximity) and $62.4 \%$ in the Middle East (low proximity). To test Hypothesis 1a, three dummy variables for brand adaptation in Turkey, Russia and the Middle East were created which were labeled as TRba, RUba and MEba, respectively, and then a series of nonparametric tests were performed. The related-sample Cochran's Q test attests that the adaptation rates change significantly as the linguistic context shifts from high to low proximity $\left(\chi^{2} C(2)=124.62, p<0.01\right)$. The examination of each pairwise comparison shows that the difference between the adaptation rates in Turkey (TRba) and the Middle East (MEba) is the greatest $(Z=10.41, p<0.01)$, followed by the difference between RUba and MEba $(Z=8.70, p<0.01)$, and then by that of TRba versus RUba $(Z=1.72, p<0.10)$. As these scores are standardized and thus comparable, it is concluded that the incidence of brand adaptation increases as one moves from the high proximity linguistic context to that of medium proximity and then to that of low proximity. The related-sample McNemar tests support this conclusion. The study finds that there is a statistically significant difference in the proportion of adapted brands in the high (TRba) versus medium (RUba) proximity contexts $\left(\chi_{\mathrm{M}}^{2}(1)=7.68\right.$, $p<0.01$ ), whereas the effect becomes stronger when the medium (RUba) and low (MEba) contexts are compared $\left(\chi_{\mathrm{M}}^{2}(1)=53.84, p<0.01\right)$. Focusing on specific adaptation strategies, the results suggest that transliteration is the major means of adaptation which significantly increases as the linguistic context shifts from high to low proximity $\left(\chi_{\mathrm{M}}^{2}(2)=144.26, p<0.01\right)$. No evidence of a significant change is found in brand name creation $\left(\chi^{2} c(2)=3.80\right.$, $p=0.15)$ and brand translation $\left(\chi^{2} c(2)=2.00\right.$,

Table 4 Brand name extension in different linguistic contexts

\begin{tabular}{|c|c|c|c|c|c|c|}
\hline \multirow{2}{*}{$\begin{array}{l}\text { Proximity to the base linguistic system (i.e., English) } \\
\text { Appropriateness of English diglossia } \\
\text { Brand extension decisions }\end{array}$} & \multicolumn{2}{|c|}{$\begin{array}{l}\text { Turkish } \\
\text { High } \\
\text { Medium }\end{array}$} & \multicolumn{2}{|c|}{$\begin{array}{l}\text { Russian } \\
\text { Medium } \\
\text { Low }\end{array}$} & \multicolumn{2}{|l|}{$\begin{array}{l}\text { Arabic } \\
\text { Low } \\
\text { High }\end{array}$} \\
\hline & Count & $\%$ & Count & $\%$ & Count & $\%$ \\
\hline Original (standardized) & 141 & 94.6 & 127 & 85.2 & 56 & 37.6 \\
\hline \multicolumn{7}{|l|}{ Modified (adapted) } \\
\hline Transliteration & 0 & 0 & 15 & 10.1 & 91 & 61.1 \\
\hline Translation & 1 & 0.7 & 2 & 1.3 & 0 & 0 \\
\hline Creation & 7 & 4.7 & 5 & 3.4 & 2 & 1.3 \\
\hline Total & 149 & 100.0 & 149 & 100.0 & 149 & 100.0 \\
\hline$\chi^{2}$ goodness-of-fit test & \multicolumn{2}{|c|}{$\chi^{2}(2)=252.29 * * *$} & \multicolumn{2}{|c|}{$\chi^{2}(3)=290.81 * * *$} & \multicolumn{2}{|c|}{$\chi^{2}(2)=80.95^{* * *}$} \\
\hline
\end{tabular}

*** $p<0.01$ 
Table 5 Slogan extension in different linguistic contexts

\begin{tabular}{|c|c|c|c|c|c|c|}
\hline \multirow{2}{*}{$\begin{array}{l}\text { Proximity to the base linguistic system (i.e., English) } \\
\text { Appropriateness of English diglossia } \\
\text { Slogan extension decisions }\end{array}$} & \multicolumn{2}{|c|}{$\begin{array}{l}\text { Turkish } \\
\text { High } \\
\text { Medium }\end{array}$} & \multicolumn{2}{|c|}{$\begin{array}{l}\text { Russian } \\
\text { Medium } \\
\text { Low }\end{array}$} & \multicolumn{2}{|c|}{$\begin{array}{l}\text { Arabic } \\
\text { Low } \\
\text { High }\end{array}$} \\
\hline & Count & $\%$ & Count & $\%$ & Count & $\%$ \\
\hline No slogan & 51 & 34.2 & 69 & 46.3 & 59 & 39.6 \\
\hline Original (standardized) & 34 & 22.8 & 15 & 10.1 & 48 & 32.2 \\
\hline \multicolumn{7}{|l|}{ Modified (adapted) } \\
\hline Translation & 34 & 22.8 & 28 & 18.8 & 22 & 14.8 \\
\hline Creation in English & 3 & 2.0 & 5 & 3.4 & 10 & 6.7 \\
\hline Creation in Local language & 27 & 18.1 & 32 & 21.5 & 10 & 6.7 \\
\hline Total & 149 & 100.0 & 149 & 100.0 & 149 & 100.0 \\
\hline$\chi^{2}$ goodness-of-fit test & \multicolumn{2}{|c|}{$\chi^{2}(3)=40.63^{* * *}$} & \multicolumn{2}{|c|}{$\chi^{2}(3)=79.82 * * *$} & \multicolumn{2}{|c|}{$\chi^{2}(3)=68.08 * * *$} \\
\hline
\end{tabular}

$* * * p<0.01$

$p=0.368)$ as the context shifts from high to low proximity.

Considering the impact of diglossia (Hypothesis 2a), it is found that brand adaptation does not vary systematically. Brand adaptation is $62.4 \%$ in the context of high diglossia, whereas it is merely $5.4 \%$ in the context of medium diglossia and $14.8 \%$ in the context of low diglossia. In light of the nonparametric test results (MEba vs. TRba, $\chi_{\mathrm{M}}^{2}(1)=81.10, \quad p<0.01$ and MEba vs. TRba, $\left.\chi_{\mathrm{M}}^{2}(1)=53.84, p<0.01\right)$, it appears that in general highly diglossic settings lead to greater brand adaptation (the main mode of adaptation being transliteration), whereas the medium to low diglossic settings result in limited brand adaptation.

Table 5 presents the slogan extension patterns. The Chisquare goodness-of-fit test statistics are significant which mean that there are statistically significant differences in the observed proportions. It can be seen that out of all the cases considered $34.2 \%$ of the brands do not feature slogans in Turkey, whereas this proportion is 39.6 and $46.3 \%$ in the Middle East and Russia, respectively $\left(\chi^{2} C(2)=13.94, p<0.01\right)$. It is found that slogan transliteration is absent in all cases.

In contrast to the brand name extension tendencies, the Middle East features the highest rate of slogan standardization (32.2\%), followed by Turkey (22.8\%) and Russia $(10.1 \%)$. Three dummy variables for slogan standardization in Turkey, Russia and the Middle East were created and labeled as TRst, RUst and MEst, respectively. The Cochran's Q test shows that differences in slogan standardization between the linguistic contexts are significant $\left(\chi^{2} C(2)=41.15, p<0.01\right)$. As corporations have a choice of featuring no slogans, a relative increase in standardization may not always mean a relative decrease in adaptation.
The adaptation rate is $28.2 \%$ in the Middle East, $43 \%$ in Turkey and $43.6 \%$ in Russia. To test Hypotheses $1 \mathrm{~b}$ and $2 \mathrm{~b}$, the authors created three dummy variables for slogan adaptation labeled as TRsa, RUsa and MEsa, respectively. Cochran's Q test was significant $\left(\chi^{2} C(2)=16.62\right.$, $p<0.01)$ indicating that the effect of proximity on slogan adaptation is non-systematic (Hypothesis 1b). Focusing on specific slogan adaptation modes, it is found the effect of proximity on slogan translation is systematically positive $\left(\chi^{2} C(2)=5.02, p<0.10\right)$, while its effect on new slogan creation in English is systematically negative $\left(\chi^{2} C(2)=5.57, p<0.10\right)$.

The pairwise comparisons and the McNemar tests show the greatest distance between MEsa (high diglossia) and RUsa (low diglossia) $\left(Z=3.61, p<0.01 ; \chi_{M}^{2}(1)=9.87\right.$, $p<0.01)$ and a statistically significant distance between MEsa (high diglossia) and TRsa (medium diglossia) $\left(Z=3.45, p<0.01 ; \chi_{\mathrm{M}}^{2}(1)=14.70, p<0.01\right)$, but a nonsignificant difference between TRsa (medium) and RUsa (low) $\left(Z=0.15, \quad p=0.87 ; \quad \chi_{\mathrm{M}}^{2}(1)=0.00, \quad p=1.00\right)$. Hence, the conclusion is that, on average, slogan adaptation is increasingly implemented as diglossia diminishes. This finding lends significant support to Hypothesis $2 b$. Moreover, the study finds that there is a negative systematic effect of diglossia on new slogan creation in a local language $\left(\chi^{2} C(2)=17.73, p<0.01\right)$.

The summary of the systematic and non-systematic effects is given in Tables 6 and 7. These tables reveal a specific relationship between linguistic proximity and diglossia. The direction of the effects is reversed (i.e., positive becomes negative, and vice versa), and the nature of the effect changes (i.e., systematic becomes non-systematic, and vice versa) as the context of the effects changes. 
Table 6 Effect of the linguistic proximity levels on brand/slogan extension

\begin{tabular}{llllll}
\hline $\begin{array}{l}\text { Proximity to the base linguistic system } \\
\text { (i.e., English) }\end{array}$ & $\begin{array}{l}\text { High } \\
\text { Turkish }(\%)\end{array}$ & $\begin{array}{l}\text { Medium } \\
\text { Russian }(\%)\end{array}$ & $\begin{array}{l}\text { Low } \\
\text { Arabic }(\%)\end{array}$ & Cochran's $Q$ & Effect \\
\hline Brand name adaptation, including & 5.4 & 14.8 & 62.4 & $\chi^{2} C(2)=124.62^{* * *}$ & Systematic, negative \\
$\quad$ Brand name transliteration & 0 & 10.1 & 61.1 & $\chi^{2} C(2)=144.26^{* * *}$ & Systematic, negative \\
Slogan standardization & 22.8 & 10.1 & 32.2 & $\chi^{2} C(2)=41.15^{* * *}$ & Non-systematic, negative \\
Slogan adaptation, including & 43 & 43.6 & 28.2 & $\chi^{2} C(2)=16.62^{* * *}$ & Non-systematic, positive \\
Slogan translation & 22.8 & 18.8 & 14.8 & $\chi^{2} C(2)=5.02^{*}$ & Systematic, positive \\
Slogan creation in English & 2.0 & 3.4 & 6.7 & $\chi^{2} C(2)=5.57^{*}$ & Systematic, negative \\
Slogan creation in local language & 18.1 & 21.5 & 6.7 & $\chi^{2} C(2)=17.73^{* * *}$ & Non-systematic, positive \\
\hline
\end{tabular}

$* * * p<0.01 ; * * p<0.05 ; * p<0.10$

Table 7 Effect of the diglossia levels on brand/slogan extension

\begin{tabular}{llllll}
\hline Appropriateness of English diglossia & $\begin{array}{l}\text { High } \\
\text { Arabic }(\%)\end{array}$ & $\begin{array}{l}\text { Medium } \\
\text { Turkish }(\%)\end{array}$ & $\begin{array}{l}\text { Low } \\
\text { Russian }(\%)\end{array}$ & Cochran's $Q$ & Effect \\
\hline Brand name adaptation, including & 62.4 & 5.4 & 14.8 & $\chi^{2} C(2)=124.62^{* * *}$ & Non-systematic, positive \\
$\quad$ Brand name transliteration & 61.1 & 0 & 10.1 & $\chi^{2} C(2)=144.26^{* * *}$ & Non-systematic, Positive \\
Slogan standardization & 32.2 & 22.8 & 10.1 & $\chi^{2} C(2)=41.15^{* * *}$ & Systematic, positive \\
Slogan adaptation, including & 28.2 & 43 & 43.6 & $\chi^{2} C(2)=16.62^{* * *}$ & Systematic, negative \\
Slogan translation & 14.8 & 22.8 & 18.8 & $\chi^{2} C(2)=5.02^{*}$ & Non-systematic, negative \\
Slogan creation in English & 6.7 & 2.0 & 3.4 & $\chi^{2} C(2)=5.57^{*}$ & Non-systematic, positive \\
Slogan creation in Local Language & 6.7 & 18.1 & 21.5 & $\chi^{2} C(2)=17.73^{* * *}$ & Systematic, negative \\
\hline
\end{tabular}

*** $p<0.01 ; * * p<0.05 ; * p<0.10$

\section{Discussion and conclusions}

This current study is an attempt to address a concern voiced by Whitelock and Fastoso (2007) that there is a dearth of studies focusing on how MNCs deal with brand extension challenges in countries located in the African, Latin American, Asia-Pacific and Middle Eastern regions. In particular, linguistic contexts with slightly varying degrees of proximity and diglossia are not well studied. Although a number of researches consider the influence of phonetic and semantic differences in brand name localization decisions (Fetscherin et al. 2012; Alon et al. 2009), the role of meta-semantics including diglossia is markedly absent from the discussion.

The current study uncovers a complex set of effects related to the impact of phonetic proximity and diglossia on corporate visual identity extension. The analysis shows that brand and slogan adaptation practices are in general subject to two distinct forces: Brand name adaptation is systematically influenced by linguistic proximity, whereas slogan adaptation is systematically dependent on diglossia. Here the systematic effect means one-to-one correspondence of the levels: High proximity is associated with high brand adaptation, medium proximity is associated with a medium extent of brand adaptation, and so on. In contrast, the effect of diglossia on brand adaptation or the effect of proximity on slogan adaptation is non-systematic. This means that although the effect is significant, there is no one-to-one match of the levels; for example, high-medium-low proximity leads to medium-low-high slogan adaptation. In general, the systematic effects appear to be more robust and meaningful to interpret. Also, the study finds that the systematic effect of linguistic proximity on brand name transliteration and slogan creation in English is negative, while its effect on slogan translation is positive. In addition, diglossia negatively impacts slogan creation in a local language. An interesting insight is that these systematic effects become non-systematic as diglossia replaces proximity as an impact factor, and vice versa.

The systematic effects of proximity and diglossia can be interpreted as two structural forces creating a general momentum and inertia of corporate visual identity extension in a given linguistic context (Hannan and Freeman; 1984; Kelly and Amburgey 1991; Stieglitz et al. 2016). Hannan and Freeman (1984) argued that organizations develop inertia by aiming to attain functional reliability through implementing familiar routines of environmental response. As environmental change becomes more dynamic, which applies to the contexts in which MNCs operate, inertia becomes an optimal choice guaranteeing 
Table 8 Corporate visual identity integration matrix

\begin{tabular}{ll}
\hline Diglossia & \\
\hline High & Low \\
\hline Linguistic proximity & \\
High & \\
I. Integration & II. Non-integration \\
LP( -$)$ Brand adaptation & LP(-) Brand adaptation \\
$\mathrm{D}(-)$ Slogan adaptation & $\mathrm{D}(+)$ Slogan adaptation \\
Low & \\
III. Non-integration & $\mathrm{IV}$. Integration \\
LP(+) Brand adaptation & $\mathrm{LP}(+)$ Brand adaptation \\
$\mathrm{D}(-)$ Slogan adaptation & $\mathrm{D}(+)$ Slogan adaptation \\
\hline
\end{tabular}

success (Stieglitz et al. 2016). This study indicates that the differential effect of proximity and diglossia gives rise to the dominant as well as recurrent patterns of brand name/ slogan extension in different linguistic contexts (Table 8).

As it is given in Table 8, the linguistic contexts with matching degrees of proximity and diglossia (I and IV) amplify the likelihood of integrated corporate visual identity. This localized integration arises when proximity hinders brand adaptation [LP(-) Brand Adaptation], while diglossia hinders slogan adaptation $[\mathrm{D}(-)$ Slogan Adaptation] simultaneously. Similarly, their enabling effect $[\mathrm{LP}(+)$ Brand Adaptation; $\mathrm{D}(+)$ Slogan Adaptation] also leads to brand/slogan extension consistency. The contexts with high proximity and low diglossia (II), and vice versa (III), exert such pressure on visual identity extension decisions that the outcome can be a non-integrated, hybrid response.

Furthermore, this study contributes to the explanation of brand/slogan extension inertia patterns in different linguistic contexts. Brand name adaptation is highly probable when the phonetic distance between linguistic systems is substantial. This result partially conforms to the commonly accepted expectation that corporate visual identity localization would be prominent in countries with dissimilar languages (Hornik 1980; Mueller 1992; Onkvisit and Shaw 1987, 1999; Papavassiliou and Stathakopoulos 1997; Ryans and Donnelly 1969; Samiee et al. 2003) and culture (Jun and Lee 2007; Melewar and Jenkins 2002; Melewar and Saunders 1998, 1999; Wheeler 2003). This research contributes further clarification. Linguistic "similarity" can be defined in many ways. The findings suggest the phonetic distance may still lead to greater adaptation incidence even when the base and host languages are very similar in terms of language family, grammar and content. Moreover, previous research finds that firms overwhelmingly localize their brands in phonetically and semantically different sociocultural contexts through the concentrated use of transliteration (Francis et al. 2002). Transliteration is usually assumed to be a kind of "sound standardization." Our results support this point to some extent while adding a nuanced understanding: Yes, brand adaptation increases as phonetic differences increase. In such cases, the main mode of adaptation is transliteration that is more prominent when linguistic proximity is low. However, the assumption of transliteration as "uniform sound" does not hold for countries such as Turkey and Russia, where phonetic proximity should have encouraged a heavy use of transliteration. In light of the positive effect of diglossia on transliteration, the decisions favoring transliteration can be understood as an attempt to assimilate foreign brand names into the local culture through the use of the meta-semantic institution.

From the inertia theory perspective, the study also finds that the proclivity to localize slogans increases if the extent of perceived appropriateness of the base language diglossia is low. The extant research, in general, predicts low proclivity to standardize slogans/advertising in the contexts of substantial linguistic differences (Usunier and Shaner 2002; Wang 1996). It also known that in highly different linguistic contexts only the most basic part of the advertising message is likely to be standardized compared to those elements that are based on creative expression (Boddewyn et al. 1986; James and Hill 1991; Sorenson and Wiechmann 1975). Notably, the previous research does not explain the counterintuitive tendency of the relatively greater incidence of slogan standardization that is observed in the substantially dissimilar phonetic and linguistic contexts (e.g., English vs. Arabic). Therefore, the impact of diglossia is a tenable explanation. Although researchers in general expect high adaptation proclivity in the Middle East, specifically in UAE and Saudi Arabia due to significant sociolinguistic, value-based and cultural differences (Langlois et al. 2012), the evidence, in contrast, shows that logo/tagline standardization is prevalent in these countries, especially when brands are considered to be of high prestige, elite and status related (Rehman 2008). It is highly likely that the use of English in slogans increases the "prestigiousness" perceptions of the brands (Steenkamp et al. 2003). Nevertheless, the conjecture of brand prestige alone cannot explain the varying degrees of slogan standardization versus adaptation proportions in different linguistic contexts (Holt et al. 2004; Steenkamp et al. 2003; Schuiling and Kapferer 2004), as the same brands with similar prestige operate in all countries under focus. Moreover, Batra et al. (2000) see the perceptions of prestige as emerging from the admiration of Western lifestyles among low income population experiencing supply scarcity. However, this is not the case in the Middle East (Sobh et al. 2014). The results suggest that the varying levels of the appropriateness of English diglossia better explain why global corporations opt for relatively high slogan standardization in the Middle East compared to Turkey and 
Russia, and conversely, high slogan adaptation in Russia when compared to Turkey and the Middle East.

\section{Brand management implications}

In the context of brand/slogan extension decisions brand managers must be conscious of two counter-reacting forces of linguistic proximity and diglossia. The systematic effects of these forces create brand/slogan adaptation inertia due to which corporate visual identity is attracted to the asymptotic position of integration versus non-integration depending on a linguistic context (Hannan and Freeman 1984; Stieglitz et al. 2016). Brand managers can use the proximity/diglossia criteria given in Tables 2 and 3 and the corporate visual identity matrix given in Table 8 to diagnose visual identity decision situations pertaining to the linguistic context under focus. The matrix can be used as a diagnostic tool to identify the likelihood of broad inertia-based local integration or non-integration. If the threat of localized non-integration is identified, then its likely impact on the consistency of brand meanings should be evaluated. It is not always that inconsistent, non-integrated visual identity becomes problematic. However, the maxim of integrated marketing communications presumes the superiority of integration over non-integration.

The case of Toyota's unique visual identity strategy discussed in the introductory section of this article can now be analyzed via the matrix. As the strategy is implemented in the Middle East where linguistic proximity is low and diglossia is high, it can be shown that this linguistic context pertains to Cell III of the matrix. This means that market pressure will give rise to inertia that leans toward greater brand name adaptation due to the proximity effect, while inhibiting slogan adaptation due to the diglossia effect. Consequently, Toyota's approach of a standardized brand name combined with a localized slogan diverges from general market inertia. In fact, such "swimming against the current" can be assessed as an innovative, radical strategy that affirms the corporation's powerful identity: Toyota is a foreign brand that can exquisitely express complex emotion-laden meanings in Arabic.

From the global perspective, consistent visual identity and integrated communication are often seen as a corporate prerogative. However, as the matrix in Table 8 shows, only high proximity-high diglossia (Cell I) contexts facilitate such ambition, as the market pressure favors the standardization of both brand names and slogans. The low proximity-low diglossia (Cell IV) contexts are particularly paradoxical as local consistency can come at the expense of global integration. Hence, brand managers can use the matrix to diagnose inertia tendencies within industries/countries and adjust their corporate visual identity strategy. The main insight this research contributes to the discussion of reconciling consistent corporate identity with requisite adaptations in different context is that some linguistic contexts (e.g., Cell I) inherently facilitate global consistency, while others (Cells II, III, IV) may create complications.

Specifically, brand managers can use the criteria given in Tables 2 and 3 to analyze subtle differences in phonetic distance and language use symbolism. The assumption that languages within the same phonographic family are similar because of their common linguistic family, grammar, and content is not feasible. Therefore, differences across cultures stemming from phonetic distance and diglossia-based symbolism should be taken into account. Also, brand managers should attend to the subtle meanings of concepts such as transliteration-as-sound standardization and brand prestige in countries with higher levels of diglossia. In such contexts, transliteration may not only have a functional purpose (e.g., sound standardization) but also operate as a means of a brand's cultural assimilation. Similarly, the use of standardized slogan should not simply be driven by brand prestigiousness perceptions; rather, brand managers must examine the cultural appropriateness of the use of a certain language in a specific linguistic context.

\section{Limitations and future research}

The current study is an initial attempt to investigate the impact of country-level variables on corporate visual identity extension decisions. It employs expert opinionbased ratings to measure linguistic proximity and diglossia. There is a possibility that consumer-based evaluations of these concepts may provide a different picture of the reality in different linguistic contexts. Hence, there is a great scope for future research. One of the possibilities is to employ a hierarchical linear modeling approach including various variables at different levels (e.g., brand, industry, country). Also, the interaction of the main factors with a number of key control factors such as country-of-origin perceptions, brand prototypicality or corporate performance indicators should be examined. In conclusion, the authors note that research related to the meta-semantics of sociolinguistic contexts in different markets is scarce. Hence, this domain offers a fertile ground for subsequent research in branding.

\section{Compliance with ethical standards}

Conflict of interest On behalf of all authors, the corresponding author states that there is no conflict of interest. 


\section{References}

Aaker, D.A. 1996. Building strong brands. New York, NY: Free Press.

Alashban, A.A., L.A. Hayes, G.M. Zinkhan, and A.L. Balazs. 2002. International brand-name standardization/adaptation: Antecedents and consequences. Journal of International Marketing 10 (3): $22-48$.

Alon, I., R.F. Littrell, and A.K.K. Chan. 2009. Branding in China: Global product strategy alternatives. The Multinational Business Review 17 (4): 123-142.

Bardakcı, A., and M. Akıncı. 2014. Türkiye'de ürün markalamada yabancı dil kullanımı: Sebepler ve sonuçlar. Tüketici ve Tüketim Araştırmaları Dergisi 6 (1): 1-26.

Bhatia, T. K. (2000) Advertising in rural India: Language, marketing communication, and consumerism. Institute for the Study of Languages and Cultures of Asia and Africa, Tokyo University of Foreign Studies, pp. 139-172.

Batra, R., Ramaswamy, V., Alden, D.L., Steenkamp, J.B.E., and Ramachander, S. 2000. Effects of brand local and nonlocal origin on consumer attitudes in developing countries. Journal of consumer psychology, 9 (2): 83-95.

Boddewyn, J.J., R. Soehl, and J. Picard. 1986. Standardization in international marketing: is Ted Levitt in fact right? Business Horizons 29 (6): 69-75.

Boddewyn, J.J., and R. Grosse. 1995. American marketing in the European Union: Standardization's uneven progress (1973-1993). European Journal of Marketing 29 (12): 23-42.

Bruneel, H. (2013). What's in a name? Chinese brand names of multinationals. http://blog.hutong-school.com/brand-name-multi nationals-china/. Date of access: January, 2016.

Chan, A.K.K., and Y.Y. Huang. 1997. Brand naming in China: A linguistic approach. Marketing Intelligence and Planning 15 (5): 227-234.

Dawar, N., and P. Parker. 1994. Marketing universals: Consumers' use of brand name, price, physical appearance, and retailer reputation as signals of product quality. Journal of Marketing 58 (2): 81-95.

Erdoğmuş, Eİ., M. Bodur, and C. Yilmaz. 2010. International strategies of emerging market firms: Standardization in brand management revisited. European Journal of Marketing 44 (9/ 10): $1410-1436$.

Fan, Y. 2002. The national image of global brands. The Journal of Brand Management 9 (3): 180-192.

Fastoso, F., and J. Whitelock. 2007. International advertising strategy: The standardisation question in manager studies: Patterns in four decades of past research and directions for future knowledge advancement. International Marketing Review 24 (5): 591-605.

Fatt, A.C. 1967. The danger of "local" international advertising. Journal of Marketing 31 (1): 60-62.

Ferguson, C.A. 1959. Diglossia. Word 15 (2): 325-340.

Fetscherin, M., I. Alon, R. Little, and A. Chan. 2012. In China? Pick your brand name carefully. Harvard Business Review 90: 706.

Francis, J., J. Lam, and J. Walls. 2002. The impact of linguistic differences on international brand name standardization: A comparison of English and Chinese brand names of Fortune-500 companies. Journal of International Marketing 10 (1): 98-116.

Hannan, M.T., and J. Freeman. 1984. Structural inertia and organizational change. American Sociological Review 49 (2): 149-164.

Hollensen, S. 2004. Global marketing: A decision-oriented approach, 3rd ed. Essex: Prentice Hall.

Holt, D.B., J.A. Quelch, and E.L. Taylor. 2004. How global brands compete. Harvard Business Review 82 (9): 68-75.

Hornik, J. 1980. Quantitative analysis of visual perception of printed advertisements. Journal of Advertising Research 20 (6): 41-48.
Hornikx, J., F. van Meurs, and A. de Boer. 2010. English or a local language in advertising? The appreciation of easy and difficult English slogans in the Netherlands. Journal of Business Communication 47 (2): 169-188.

Hudson, A. 2002. Outline of a theory of diglossia. International Journal of the Sociology of Language 157 (September): 1-48.

Jain, S.C. 1989. Standardization of international marketing strategy: Some research hypotheses. Journal of Marketing 53 (1): 70-79.

James, W.L., and J.S. Hill. 1991. International advertising messages: To adapt or not to adapt (that is the question). Journal of Advertising Research 31 (3): 65-71.

Jun, J.W., and H.S. Lee. 2007. Cultural differences in brand designs and tagline appeals. International Marketing Review 24 (4): 474-491.

Keller, K.L., S.E. Heckler, and M.J. Houston. 1998. The effects of brand name suggestiveness on advertising recall. Journal of Marketing 62 (1): 48-57.

Keller, K.L. 1993. Conceptualizing, measuring and managing customer-based brand equity. Journal of Marketing 57 (1): 1-22.

Kelly, D., and T.L. Amburgey. 1991. Organizational inertia and momentum: A dynamic model of strategic change. Academy of Management Journal 34 (3): 591-612.

Krishna, A., and R. Ahluwalia. 2008. Language choice in advertising to bilinguals: Asymmetric effects for multinationals versus local firms. Journal of Consumer Research 35 (4): 692-705.

Langlois, E., A. Langlois, and D. Havens. 2012. Marketing a United States multinational brand in the United Arab Emirates. Journal of Marketing Development and Competitiveness 6 (5): 115.

Li, F., and N.H. Shooshtari. 2003. Brand naming in China: Sociolinguistic implications. Multinational Business Review 11 (3): 3-22.

Lowrey, T.M., and L.J. Shrum. 2007. Phonetic symbolism and brand name preference. Journal of Consumer Research 34 (3): 406-414.

Melewar, T.C., and E. Jenkins. 2002. Defining the corporate identity construct. Corporate Reputation Review 5 (1): 76-90.

Melewar, T.C., and J. Saunders. 1999. International corporate visual identity: Standardization or localization? Journal of International Business Studies 30 (3): 583-598.

Melewar, T.C., and J. Saunders. 1998. Global corporate visual identity systems Standardization, control and benefits. International Marketing Review 15 (4): 291-308.

Mueller, B. 1992. Standardization vs. specialization: An examination of westernization in Japanese advertising. Journal of Advertising Research 32 (1): 15-24.

Nord, C. 1994. Translation as a process of linguistic and cultural adaptation. Teaching Translation and Interpreting 2: 59-67.

Onkvisit, S., and J.J. Shaw. 1999. Standardized international advertising: Some research issues and implications. Journal of Advertising Research 39 (6): 19-24.

Onkvisit, S., and J. Shaw. 1987. Self-concept and image congruence: Some research and managerial implications. Journal of Consumer Marketing 4 (1): 13-23.

Papavassiliou, N., and V. Stathakopoulos. 1997. Standardization versus adaptation of international advertising strategies: Towards a framework. European Journal of Marketing 31 (7): 504-527.

Piller, I. 2003. Advertising as a site of language contact. Annual Review of Applied Linguistics 23: 170-183.

Quelch, J. 1999. Global brands: Taking stock. Business Strategy Review 10 (1): 1-14.

Rehman, A. 2008. Dubai \& Co.: Global strategies for doing business in the Gulf States. New York: McGraw Hill Education.

Ryans Jr., J.K., and J.H. Donnelly Jr. 1969. Standardized global advertising, a call as yet unanswered. The Journal of Marketing 33 (2): $57-60$. 
Samiee, S., I. Jeong, J.H. Pae, and S. Tai. 2003. Advertising standardization in multinational corporations: The subsidiary perspective. Journal of Business Research 56 (8): 613-626.

Sandler, D.M., and D. Shani. 1992. Brand globally but advertise locally? An empirical investigation. International Marketing Review 9 (4): 18-31.

Schmid, S., and T. Kotulla. 2011. 50 years of research on international standardization and adaptation-From a systematic literature analysis to a theoretical framework. International Business Review 20 (5): 491-507.

Schuiling, I., and J.N. Kapferer. 2004. Real differences between local and international brands: Strategic implications for international marketers. Journal of International Marketing 12 (4): 97-112.

Sobh, R., R. Belk, and J. Gressel. 2014. Mimicry and modernity in the Middle East: Fashion invisibility and young women of the Arab Gulf. Consumption Markets and Culture 17 (4): 392-412.

Sorenson, R.Z., and U.E. Wiechmann. 1975. How multinationals view marketing standardization. Harvard Business Review 53 (3): $38-54$.

Steenkamp, J.B.E., R. Batra, and D.L. Alden. 2003. How perceived brand globalness creates brand value. Journal of International Business Studies 34 (1): 53-65.

Stieglitz, N., T. Knudsen, and M.C. Becker. 2016. Adaptation and inertia in dynamic environments. Strategic Management Journal 37 (9): 1854-1864.

Takashi, K. 1990. A sociolinguistic analysis of English borrowings in Japanese advertising texts. World Englishes 9 (3): 327-341.

Terpstra, V., and R. Sarathy. 2000. International marketing, 8th ed. Orlando, FL: Dryden Press.

The AMA. (2017). Marketing dictionary: The American Marketing Association. https://www.ama.org/resources/pages/dictionary. aspx?dLetter=B.

Usunier, J.C., and J. Shaner. 2002. Using linguistics for creating better international brand names. Journal of Marketing Communications 8 (4): 211-228.

Walters, P.G. 1986. International marketing policy: A discussion of the standardization construct and its relevance for corporate policy. Journal of International Business Studies 17 (2): 55-69.

Wang, C.L. 1996. The degree of standardization: A contingency framework for global marketing strategy development. Journal of Global Marketing 10 (1): 89-107.
Wheeler, A. 2003. Designing brand identity: A complete guide to creating, building, and maintaining strong brands. Hoboken, NJ: Wiley.

Whitelock, J., and F. Fastoso. 2007. Understanding international branding: Defining the domain and reviewing the literature. International Marketing Review 24 (3): 252-270.

Zaltman, G., and M. Wallendorf. 1979. Consumer behavior, basic findings and management implications. Hoboken, NJ: Wiley.

Zhang, S., and B.H. Schmitt. 2001. Creating local brands in multilingual international markets. Journal of Marketing Research 38 (3): 313-325.

Dr Djavlonbek Kadirov ( $\mathrm{PhD}$, University of Waikato) is a lecturer in marketing at the School of Marketing and International Business, Victoria University of Wellington, New Zealand. Djavlonbek's research interests include marketing systems, sustainable marketing/consumption, marketing ethics, and global brands. His research has appeared in journals such as the Journal of Macromarketing, Journal of Marketing Management, Journal of Business Research, and Consumption Markets \& Culture.

Dr Ahmet Bardakcı is a Professor of Marketing at the Department of Business, the University of Pamukkale, Turkey. He serves as the chair of Production Management and Marketing Department since 2007. He holds PhD and MSc in Marketing from the University of Salford (UK) where he was involved in research on mass customization. His research interests include Marketing Research, International Marketing, and Strategic Marketing.

Murat Kantar is a research assistant at the Department of International Trade and Finance, University of Pamukkale, Turkey. Murat received his MSc from the University of Pamukkale and currently conducting his doctorate under the supervision of Dr Ahmet Bardakc1. His main research interests include International Business, Internet Marketing, and Consumer Behavior. 